\title{
Effects and mechanisms of left ventricular false tendons on functional mitral regurgitation in patients with severe cardiomyopathy
}

\author{
Mehul R. Bhatt, MD, Carlos E. Alfonso, MD, Amar M. Bhatt, BS, Sangmin Lee, MD, \\ Alexandre C. Ferreira, MD, Tomas A. Salerno, MD, and Eduardo de Marchena, MD
}

Objective: False tendons in the left ventricle are commonly observed. Preliminary observations associate false tendons with less functional mitral regurgitation.

\begin{abstract}
Methods: Echocardiograms demonstrating severe cardiomyopathy (ejection fraction $\leq 30 \%$ ) were retrospectively examined for left ventricular false tendons. The ejection fraction, cause of left ventricular systolic dysfunction, left ventricular diastolic dimensions, severity of mitral regurgitation, mitral annular diameter, mitral valve coaptation depth, mitral valve coaptation area, and orientation of false tendon were evaluated. The patients with false tendons were compared with a control group with cardiomyopathy without false tendons.
\end{abstract}

Results: A cohort of patients $(\mathrm{n}=82)$ with severe left ventricular systolic dysfunction (mean ejection fraction, $21 \%$ ) and false tendons were compared with a control group with similar left ventricular dysfunction and no false tendons $(\mathrm{n}=121$; mean ejection fraction, $20 \% ; P=.10)$. The patients with false tendons had similar left ventricular diastolic internal dimensions compared with the control group $(5.99$ and $6.18 \mathrm{~cm}$, respectively; $P=.086$ ). Yet patients with false tendons had a very low incidence of severe functional mitral regurgitation compared with the control group $(4.9 \%$ vs $27 \%, P<.001)$. Patients with false tendons had significantly smaller mitral annular diameters ( 3.57 vs $4.03 \mathrm{~cm}, P<.001$ ), shorter mitral valve coaptation depths (0.89 vs $1.24 \mathrm{~cm}, P<.001$ ), and reduced coaptation areas $\left(1.61 \mathrm{vs} 2.52 \mathrm{~cm}^{2}, P<.001\right)$ than the control group. The reduction of mitral regurgitation was more significant for patient with transverse midcavity false tendons.

Conclusions: Patients with false tendons and cardiomyopathy have less severe mitral regurgitation. The mechanism for the reduction in functional mitral regurgitation might be less mitral valve deformation, specifically lower coaptation depth and coaptation area when a false tendon is present.

Functional mitral regurgitation (MR) is mitral valve insufficiency in the absence of primary mitral valve disease but rather caused by myocardial dysfunction. Functional MR worsens prognosis in both ischemic and nonischemic cardiomyopathies. ${ }^{1-3}$ The mechanisms leading to MR despite normal leaflet structure stem from a vicious cycle of left ventricular (LV) dysfunction, LV sphericity, mitral annular dilation (Carpentier's type I MR), papillary muscle displacement (Carpentier's type IIIb MR), and further LV dilation. ${ }^{4-9}$ The current treatment of functional MR includes mitral valve replacement or repair, edge-to-edge mitral leaflet approximation (Alfieri stitch), mitral annular reinforcement, papillary muscle repositioning, and emerging percutaneous devices. ${ }^{4,10-12}$

False tendons in the left ventricle are commonly observed during routine 2-dimensional echocardiographic analysis. False tendons (otherwise called false chords or bands) are

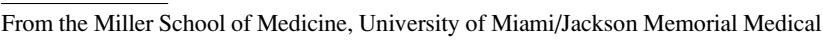
Center, Miami, Fla.

Received for publication Jan 31, 2008; revisions received Aug 8, 2008; accepted for publication Oct 3, 2008; available ahead of print May 11, 2009.

Address for reprints: Eduardo de Marchena, MD, PO Box 016960, University of Miami/Jackson Memorial Hospital, Division of Cardiology (D-62), Miami, FL 33101 (E-mail: emarchen@med.miami.edu).

J Thorac Cardiovasc Surg 2009;138:1123-8

$0022-5223 / \$ 36.00$

Copyright (c) 2009 by The American Association for Thoracic Surgery

doi:10.1016/j.jtcvs.2008.10.056
}

defined as single or multiple structures that traverse the LV cavity with no connection to the valve leaflets. ${ }^{13}$ The incidence of false tendons ranges from $18 \%$ to $26 \%$ during 2-dimensional echocardiographic analysis to a reported $34 \%$ incidence at autopsy. ${ }^{13-15}$ Histologically, false tendons are highly vascularized and are comprised of fibrous tissue, myocardial cells, or conductive Purkinje cells. ${ }^{13,14,16}$ False tendons have been associated with male sex, premature ventricular contractions, and possibly idiopathic ventricular tachycardia, but no data are available defining their hemodynamic characteristics. ${ }^{15,17,18}$

The concept for this study began with the observation that patients with severely hypokinetic ventricles and LV false tendons in the midcavity zone appeared to have improved clinical outcomes. ${ }^{19}$ Furthermore, it was hypothesized that by structurally supporting a failing hypokinetic left ventricle, a false tendon might prevent or diminish functional MR. The purpose of this study was to analyze the effect of false tendons on LV hemodynamics, specifically MR, in patients with severe cardiomyopathy.

\section{MATERIALS AND METHODS \\ Study Cohort}

The echocardiogram database from a tertiary-care medical center in Miami, Florida, was retrospectively searched from April 2003 to August 2006 with the terms "false tendon," "false chord," and "left ventricular band" 


$$
\begin{aligned}
& \text { Abbreviations and Acronyms } \\
& \begin{aligned}
\mathrm{CA} & =\text { coaptation area } \\
\mathrm{CD} & =\text { coaptation depth } \\
\mathrm{EF} & =\text { ejection fraction } \\
\mathrm{LV} & =\text { left ventricular } \\
\mathrm{MD} & =\text { mitral annular diameter } \\
\mathrm{MR} & =\text { mitral regurgitation }
\end{aligned}
\end{aligned}
$$

for all transthoracic echocardiograms matching these terms. A subset of these echocardiograms with false tendons and cardiomyopathy with severe LV dysfunction (ejection fraction $[\mathrm{EF}], \leq 30 \%$ ) were isolated, and these echocardiograms were reviewed to confirm the presence of a false tendon. The orientation of the false tendon was noted and classified as (1) transverse midcavity if the chord attached the papillary muscles or opposing LV walls in the mid third of the LV cavity and (2) apical if at least 1 attachment point of the chord was in the apical portion of the LV cavity.

\section{Control Group}

Sequential patients from the same time period as the false tendon group with the echocardiographic descriptor severe LV dysfunction and EFs of less than $30 \%$ were used as a control group for comparison. These echocardiograms were reviewed to confirm the absence of a false tendon.

The echocardiograms and patients' charts for both the study cohort and control group were reviewed for age, sex, EF, cause of LV systolic dysfunction (ischemic vs nonischemic cardiomyopathy), LV end-diastolic internal dimension in parasternal long-axis view, LV posterior wall diastolic dimension, and interventricular septum diastolic dimension. The most recent electrocardiogram at the time of the index echocardiogram was reviewed, and the underlying ventricular rhythm, any conduction delay, and QRS duration were noted and recorded. Patients with a history of mitral valve surgery, mitral valve endocarditis, mitral valve prolapse, rheumatic disease, severe mitral annular calcification, or images technically inadequate for false tendon or MR grading were excluded from the analysis. Although few patients had significant aortic valvular disease, it was not a prespecified exclusion criteria. All studies were recorded and analyzed on Philips SONOS 5500 with Xcelera 1.2 software (Philips Medical Systems, Bothell, Wash) or GE Vivid 7 with EchoPAC PC 4.0.03 software (General Electric Healthcare Co, Chalford St Giles, United Kingdom).

\section{MR Quantification}

MR was graded as none, mild, moderate, or severe by an independent and separate echocardiographer, and the grading of MR was not adjusted by the study personnel to eliminate any possible bias. MR was assessed in multiple views in all patients and was graded according to standard echocardiographic criteria. If no regurgitation jet was seen based on Doppler color flow in multiple views, the MR was graded as none. MR was graded as mild if visually the Doppler color jet filled less than $20 \%$ of the left atrial cavity. The grading was defined as moderate if visually the Doppler color regurgitation jet filled $20 \%$ or more of the left atrial cavity. MR was defined as severe only if there was at least a moderate Doppler color regurgitation jet with either systolic flow reversal in the pulmonary veins or if the proximal isovelocity surface area method resulted in an effective orifice area of at least $0.4 \mathrm{~cm}^{2}$.

\section{Mitral Valve Anatomy}

All patients' echocardiograms were examined for the mitral annular diameter (MD) and mitral valve coaptation depth (CD) in the midsystole apical 4-chamber view (Figure 1). The MD was defined as the distance between the hinge points of the anterior and posterior mitral valve leaflets. The $\mathrm{CD}$

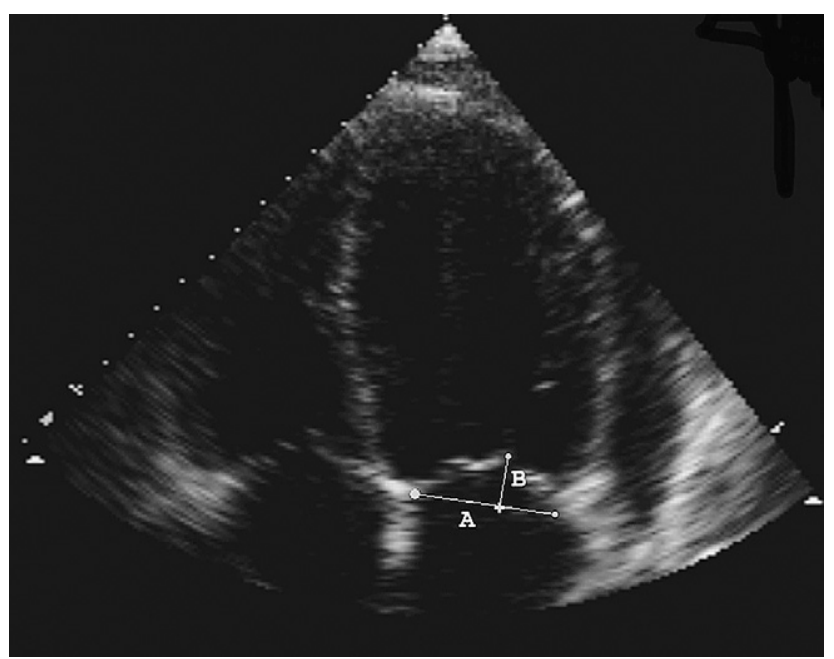

FIGURE 1. Measurement of mitral annular diameter and mitral valve coaptation depth was done in the 4-chamber apical views during midsystole. $A$, Mitral annular diameter was defined as the distance between the hinge points of the anterior and posterior mitral valve leaflets. B, Coaptation depth was measured as the length from the mitral annular plane to the point at which the mitral leaflets touch during systole.

measures the length from the mitral annular plane to the point at which the mitral leaflets touch during systole. These parameters were used to calculate the coaptation area $(\mathrm{CA} ; \mathrm{CA}=0.5 \times \mathrm{MD} \times \mathrm{CD})$. $\mathrm{CA}$ is a measure of mitral valve deformation.

\section{Statistical Analysis}

All continuous variables were expressed as the mean \pm standard deviation. Patient sex, cause of cardiomyopathy, percentage of moderate-to-severe $\mathrm{MR}$, and percentage of severe MR were expressed as descriptive variables. the Student's $t$ test and $z$ test for population proportions were used to compare the continuous and descriptive variables, respectively, and $\chi^{2}$ analysis was used to compare the cause of cardiomyopathy in the false tendon group versus that seen in the control group.

\section{RESULTS}

Echocardiographic database review found 396 patients with false tendons. A subset of 82 patients with severe LV dysfunction $(\mathrm{EF}, \leq 30 \%)$ was isolated, and their echocardiographic characteristics and causes of cardiomyopathy were recorded (Table 1). The orientations of the false tendons in these 82 patients were as follows: transverse midcavity, 56 patients; apical, 26 patients. The control group consisted of 121 patients with severe $L V$ dysfunction $(E F, \leq 30 \%$ ) and no false tendons, which was confirmed by means of re-evaluation of the echocardiograms. The echocardiographic parameters and clinical data for the control group were also recorded (Table 1). There was no statistical difference in the mean EF between the false tendon group and the control group (mean EF, $21 \% \pm 6.4 \%$ vs $20 \% \pm 5.2 \% ; P=.10$ ), and the median $\mathrm{EF}$ was $20 \%$ in both groups. The cause of cardiomyopathy did not differ significantly between the false tendon cohort and the control group, although there was a trend toward more nonischemic cardiomyopathies in the false tendon cohort (Table 1). 
TABLE 1. Characteristics of 82 patients with false tendons and EFs of $30 \%$ or less compared with control subjects with EFs of $30 \%$ or less and no false tendon

\begin{tabular}{|c|c|c|c|}
\hline & False tendon group & Control group & $P$ value \\
\hline No. of subjects & 82 & 121 & - \\
\hline Age $(y)$ & $57 \pm 14$ & $58 \pm 12$ & .311 \\
\hline Male sex $(\%)$ & 80 & 72 & .102 \\
\hline Mean EF (\%) & $21.4 \pm 6$ & $20.4 \pm 5$ & .103 \\
\hline Median EF $(\%)$ & 20 & 20 & - \\
\hline Left ventricular internal dimension, diastole $(\mathrm{cm})$ & $6.0 \pm 0.9$ & $6.2 \pm 1.1$ & .086 \\
\hline Interventricular septal dimension, diastole $(\mathrm{cm})$ & $1.0 \pm 0.2$ & $0.9 \pm 0.2$ & .115 \\
\hline Left ventricular posterior wall dimension, diastole $(\mathrm{cm})$ & $0.9 \pm 0.2$ & $1.0 \pm 0.2$ & .217 \\
\hline \multicolumn{4}{|l|}{ Cause of cardiomyopathy $(\%)$} \\
\hline Ischemic & 38 & 49 & .1622 \\
\hline Nonischemic & 61 & 50 & .1803 \\
\hline Unknown & 1 & 1 & .7808 \\
\hline Mitral regurgitation ( $\%$ moderate to severe) & 33 & 60 & .001 \\
\hline Mitral regurgitation $(\%$ severe $)$ & 4.9 & 27 & .001 \\
\hline QRS duration (ms) & $110 \pm 30$ & $107 \pm 29$ & .59 \\
\hline Mitral annular diameter $(\mathrm{cm})$ & $3.6 \pm 0.7$ & $4.0 \pm 0.5$ & .001 \\
\hline Coaptation depth $(\mathrm{cm})$ & $0.90 \pm 0.3$ & $1.2 \pm 0.3$ & .001 \\
\hline Coaptation area $\left(\mathrm{cm}^{2}\right)$ & $1.6 \pm 0.6$ & $2.5 \pm 0.7$ & .001 \\
\hline
\end{tabular}

$E F$, Ejection fraction.

\section{Dimensions}

The patients with false tendons had similar LV diastolic internal dimensions compared with those seen in the control group (5.99 and $6.18 \mathrm{~cm}, P=.086$ ), although there was a trend toward less LV dilation in patients with false tendons (Table 1).

\section{Mitral Regurgitation}

Patients with false tendons had lower proportions of at least moderate $\mathrm{MR}$ than the control group without false tendons (33\% vs $60 \%, P<.001$, Table 1$)$. Furthermore, there was also a very low incidence of severe MR in patients with false tendons and severe cardiomyopathy compared with that seen in the control group $(4.9 \%$ vs $27 \%$, $P<.001$, Figures 2 and 3). Subgroup analysis by cause of cardiomyopathy showed that regardless of the cause, the incidence of moderate-to-severe MR was statistically less in patients with false tendons in contrast to control subjects for ischemic $(29 \%$ vs $54 \%, P=.011)$ and nonischemic (34\% vs $67 \%, P<.001)$ cardiomyopathy.

\section{Mitral Valve Anatomy}

Patients with false tendons had significantly smaller MDs (3.57 vs $4.03 \mathrm{~cm}, P<.001)$ and shorter mitral valve CDs $(0.89$ vs $1.24 \mathrm{~cm}, P<.001)$ than seen in the control group (Table 1). The mitral valves were less deformed in the false tendon group, with a calculated CA of $1.61 \pm 0.64$ versus $2.52 \pm 0.72 \mathrm{~cm}^{2}$ in the control group $(P<.001)$.

\section{False Tendon Orientation}

False tendons with a midcavity transverse orientation had statistically shorter CDs $(P=.01)$ and smaller CAs $(P=$
$.005)$, as well as statistically lower rates of severe MR ( $P$ $<.001$ ), than apical false tendons (Table 2). The prevention of at least moderate MR was limited to patients with midcavity transverse false tendons $(P<.001)$ and not to apical false tendons $(P=.27)$ when either orientation was compared with results seen in control subjects.

\section{Electrocardiographic Measure of LV Synchrony}

After excluding patients with a paced ventricular rhythm, the QRS duration between the study cohort and the control group did not differ significantly $(110 \pm 30$ vs $107 \pm 29$ ms, respectively; $P=.59$ ).

\section{DISCUSSION}

To date, there are no published data on the effect of false tendons on MR. This study suggests that LV false tendons affect the severity of functional MR in patients with severe cardiomyopathy and severely reduced LV systolic function, regardless of whether the cause is ischemic or nonischemic in nature, by influencing the subvalvular apparatus. Further analysis showed that midcavity false tendons had less mitral valve deformation and reduced MR than apical false tendons.

The mechanisms of functional MR are complex. Recent data incorporating quantitative MR determination, cardiac magnetic resonance imaging, 3-dimensional echocardiographic analysis, and animal models of cardiomyopathy have uniformly shown that the presence and degree of functional MR is unrelated to the severity of LV dysfunction in both ischemic and nonischemic cardiomyopathy., ${ }^{4,7,20}$ Rather, the pathophysiology of functional MR is related to the subvalvular apparatus. Prior studies of the relationship of mitral annular dilation have shown that although the 

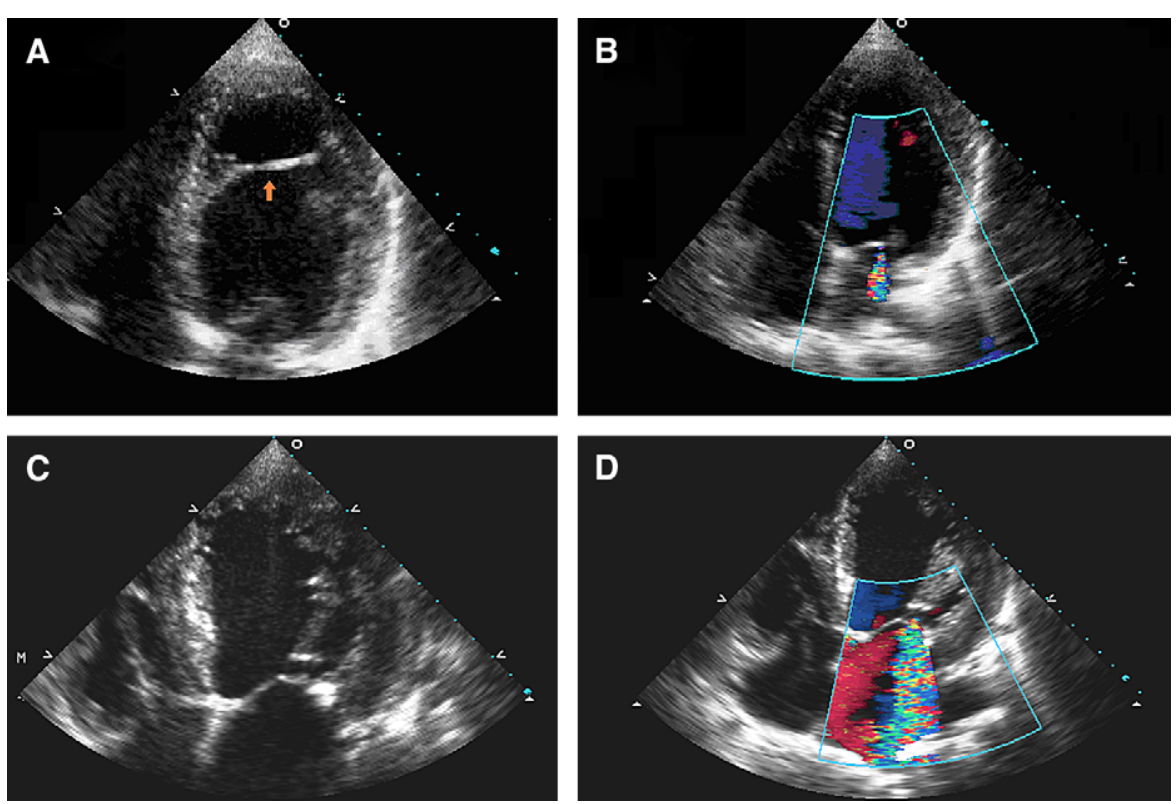

FIGURE 2. Panel A shows the 4-chamber apical echocardiogram of a 46-year-old hypertensive man with nonischemic cardiomyopathy and a left ventricular ejection fraction of $20 \%$, demonstrating a large transverse midcavity false tendon from the septum to the lateral wall (arrow). The mitral annular diameter and coaptation depth were measured at $3.8 \mathrm{~cm}$ and $0.9 \mathrm{~cm}$, respectively. Panel B shows a Doppler echocardiogram across the mitral valve demonstrating only mild mitral insufficiency. In contrast, panel $\mathrm{C}$ demonstrates the apical 4-chamber echocardiographic view for a 61-year-old woman with type 2 diabetes and ischemic cardiomyopathy with a dilated left ventricle measured at $8 \mathrm{~cm}$, an estimated left ventricular ejection fraction of $20 \%$, and no false tendon with a measured mitral annular diameter and coaptation depth of $4.5 \mathrm{~cm}$ and $1.8 \mathrm{~cm}$, respectively. Panel D shows severe mitral regurgitation by means of Doppler echocardiographic analysis, with evidence of pulmonary vein reversal and a regurgitant jet filling more than $20 \%$ of the left atrium.

mitral valve annulus dilates symmetrically in both ischemic and nonischemic cardiomyopathies, MD does not correlate with MR severity or cause of cardiomyopathy. ${ }^{8,9,21} \mathrm{CD}$ and $\mathrm{CA}$ are emerging diagnostic and prognostic parameters linking functional MR to mitral subvalvular deformation and leaflet tenting. ${ }^{5,6,22}$ Mechanistically, dysfunctional myocardium displaces papillary muscles that tether and pull the mitral leaflets toward the apex during systole. This apical displacement of the mitral leaflets leads to increased CD and CA with incomplete leaflet coaptation and thus functional MR. ${ }^{4,6} \mathrm{CD}$ and $\mathrm{CA}$ are parameters that can be incorporated into routine 2-dimensional echocardiographic examination. $\mathrm{CD}$ and $\mathrm{CA}$ have been shown to be increased in patients with cardiomyopathy, and $\mathrm{CD}$ and $\mathrm{CA}$ correlate proportionally to quantitatively determined mitral effective regurgitant orifice area. ${ }^{6}$ There are conflicting data as to the mechanisms of functional MR in ischemic versus nonischemic cardiomyopathies. Recent data concluded that CD was a major determinant of the degree of MR in only ischemic cardiomyopathy, whereas previously, a similar correlation between the mitral tenting area and MR in all types of cardiomyopathy was reported. ${ }^{5,6} \mathrm{CD}$ and $\mathrm{CA}$ also contribute prognostic data; a $\mathrm{CD}$ of greater than $1.1 \mathrm{~cm}$ and a CA of greater than $1.7 \mathrm{~cm}^{2}$ have been shown to be predictors of failure of mitral valve surgical repair or replacement. ${ }^{23,24}$

Our current results demonstrated a significantly decreased amount of MR in patients with cardiomyopathy and false tendons. The observed association between false tendons and less functional MR might have various explanations. False tendons are histologically comprised of fibrous tissue, myocardial cells, and/or conductive Purkinje cells, ${ }^{13,14,16}$ and therefore they might provide some degree of tethering support to the left ventricle, an alternate conductive circuit, or some combination of both. It is unclear by which mechanism the false tendons might act to reduce the degree of mitral insufficiency.

If significant electrical conduction is present through the conductive tissue within the false tendons, then they could hypothetically serve to make LV depolarization more homogenous and overall improve LV synchrony. Cardiac resynchronization reduces MR by improving LV mechanical synchrony, which leads to an increase in LV longitudinal function and a reduction in subvalvular traction and less apical displacement of coaptation. ${ }^{25}$ Although an imperfect measure, QRS duration is a rough estimate of ventricular synchrony ${ }^{26}$ and has been used as a criterion for evaluating patients for resynchronization therapy with biventricular pacing therapy. ${ }^{27}$ In our study the QRS duration in the study cohort did not differ significantly from that seen in the control group, suggesting that improved LV synchrony might not be a causative factor in the diminished MR observed in patients with false tendons. Unfortunately, given that this was a retrospective study, we were unable to evaluate echocardiographic measures of dysynchrony. However, it 


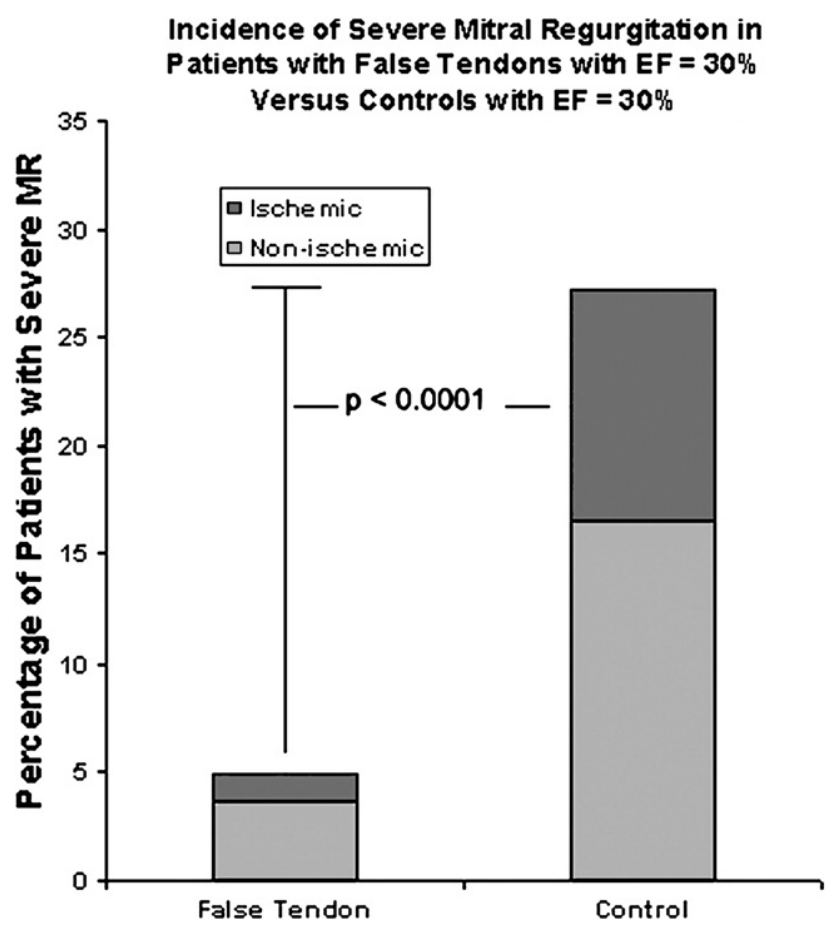

FIGURE 3. Incidence of severe mitral regurgitation $(M R)$ according to the presence or absence of a false tendon and the cause of cardiomyopathy. Overall, patients with false tendons and a cardiomyopathy had a significantly lower percentage of severe mitral regurgitation compared with control subjects. $E F$, Ejection fraction.

might be interesting for future research to prospectively assess the role, if any, that false tendons might have on echocardiographic markers of LV synchrony.

An alternative explanation is that a reinforcing false tendon serves a role to buttress the failing, dilated left ventricle. Although the trend for less LV dilation in patients with false tendons was not significant in our study, the false tendons might have a role at the subvalvular level to improve overall LV geometry. By limiting papillary muscle displacement, despite severe LV dysfunction, false tendons might result in less apical tenting of the mitral leaflets in systole. This can be directly assessed by measuring $\mathrm{CD}$ and CA. In this study patients with false tendons had decreased CDs and CAs compared with those seen in control subjects. A transverse midcavity orientation of false tendon had distinctly lower rates of MR with less mitral valve deformation (lower $\mathrm{CD}$ and $\mathrm{CA}$ ) than seen in either control or apically oriented false tendons. In fact, the subgroup of patient with apical false tendons did not have significantly different rates of moderate-to-severe MR compared with that seen in control subjects (54\% vs $60 \%, P=.27)$. Patients with transverse midcavity-positioned false tendons had preserved subvalvular geometry (CD and CA) and statistically less functional MR than either control or apically oriented false tendons. Perhaps midcavity transverse false tendons are mechanically aligned to absorb LV distorting forces and counteract
TABLE 2. Comparison of patients based on orientation of false tendons

\begin{tabular}{lccc}
\hline & $\begin{array}{c}\text { False tendon } \\
\text { (transverse) }\end{array}$ & $\begin{array}{c}\text { False tendon } \\
\text { (apical) }\end{array}$ & $\boldsymbol{P}$ value \\
\hline No. of subjects & 56 & 26 & - \\
Age (y) & $57 \pm 13$ & $57 \pm 16$ & .47 \\
Male sex (\%) & 80 & 81 & .48 \\
EF (\%) & $21.7 \pm 6$ & $21.0 \pm 7$ & .32 \\
Mitral regurgitation & 23 & 54 & .003 \\
$\quad(\%$ moderate to severe) & & & \\
Mitral regurgitation $(\%$ severe) & 1.8 & 12 & .001 \\
QRS duration (ms) & $120 \pm 35$ & $106 \pm 28$ & .08 \\
Mitral annular diameter (cm) & $3.6 \pm 0.6$ & $3.6 \pm 0.8$ & .39 \\
Coaptation depth $\left(\mathrm{cm}^{2}\right)$ & $0.8 \pm 0.2$ & $1.0 \pm 0.3$ & .01 \\
Coaptation area $\left(\mathrm{cm}^{2}\right)$ & $1.5 \pm 0.5$ & $1.9 \pm 0.8$ & .0049 \\
\hline
\end{tabular}

$E F$, Ejection fraction.

papillary muscle displacement, thus possible explaining less functional MR in this subgroup. Additionally, because of a false tendon, there is less negative global remodeling of the dysfunctional ventricle, as witnessed by a significantly smaller MD and a nonsignificant trend toward decreased LV diastolic internal dimension. These data analyzing false tendons and MR are unique in that no previous study has studied false tendons as a natural structural tether in cardiomyopathy or the interaction of false tendons with subvalvular mechanisms. In fact, no positive hemodynamic attribute has ever been associated with false tendons.

The reduction of functional MR was apparent and statistically significant in both ischemic and nonischemic cardiomyopathies. Therefore because there is a similar hemodynamic benefit of false tendons, common mechanisms leading to functional MR might be present in ischemic and nonischemic cardiomyopathies.

The conclusions of our data have some similarities to some emerging treatments of functional MR. Various surgical and percutaneous therapies that target the mitral valve leaflets are currently under development. In addition, some therapies are emerging that target the left ventricle or subvalvular apparatus with the hopes of improving LV remodeling. A surgically implanted subvalvular strut that is tightened across the ventricle with the purpose of repositioning the papillary muscles and reducing functional MR is under development. ${ }^{28}$ Recent experiments in both a canine cardiomyopathy model and 1-year follow-up of $11 \mathrm{hu}$ man subjects with the subvalvular strut implanted at the time of coronary artery bypass grafting showed improvements in functional MR caused by a reduction in MD and papillary muscle repositioning. ${ }^{28-30}$ The data from these trials with surgically implanted struts is congruent with our current findings in which LV false tendons also reduce functional MR, possibly by preserving subvalvular anatomy. Further research needs to elucidate this mechanism more clearly, but it might suggest that future therapies that target the subvalvular apparatus and decrease CA and 
overall improve LV geometry might work to decrease functional MR.

\section{Limitations}

This study has several limitations. Patients with false tendons were identified retrospectively from an echocardiographic database. Therefore some eligible patients with false tendons might not have been identified or included in the study. There was no assessment of the timing of the echocardiogram, including investigation of medications, volume status, time period of cardiomyopathy, or patient condition, that could affect MR across the false tendon and control groups. In addition, the echocardiographic quantification of MR, although based on standard criteria as described, was not reassessed and was dependent on the initial echocardiographic interpretation. Although limitations are present in this retrospective analysis, these limitations would be expected to affect the false tendon and control group equally. Although it might be interesting for future investigation, we did not collect any prospective follow-up data as to the clinical significance of the decrease in functional MR in patients with false tendons. Overall, the association between false tendons and decreased functional MR was strong.

\section{CONCLUSION}

Patients with false tendons and severe LV dysfunction have tethering effects yielding positive hemodynamic characteristics, specifically less severe MR. The mechanism for the reduction in functional MR might be a reduction in papillary muscle separation and mitral valve deformation measured by the reduced $\mathrm{CD}$ and $\mathrm{CA}$ when a false tendon is present. The benefit of false tendons is most apparent when aligned in the transverse midcavity orientation.

\section{References}

1. Blondheim DS, Jacobs LE, Kotler MN, Costacurta GA, Parry WR. Dilated cardiomyopathy with mitral regurgitation: decreased survival despite a low frequency of left ventricular thrombus. Am Heart J. 1991;122:763-71.

2. Lamas GA, Mitchell GF, Flaker GC, Smith SC Jr, Gersh BJ, Basta L, et al. Clinical significance of mitral regurgitation after acute myocardial infarction. Circulation. 1997;96:827-33.

3. Romeo F, Pelliccia F, Cianfrocca C, Gallo P, Barilla F, Cristofani R, et al. Determinants of end-stage idiopathic dilated cardiomyopathy: a multivariate analysis of 104 patients. Clin Cardiol. 1989;12:387-92.

4. Levine RA, Schwammenthal E. Ischemia mitral regurgitation on the threshold of a solution: from paradoxes to unifying concepts. Circulation. 2005;112:745-58.

5. Nagasaki M, Nishimura S, Ohtaki E, Kasegawa H, Matsumura T, Nagayama M, et al. The echocardiographic determinants of functional mitral regurgitation differ in ischemic and non-ischemic cardiomyopathy. Int J Cardiol. 2006;108:171-6.

6. Yiu SF, Enriquez-Sarano M, Tribouilloy C, Seward JB, Tajik AJ. Determinants of the degree of functional mitral regurgitation in patients with systolic left ventricular dysfunction: a quantitative clinical study. Circulation. 2000;102:1400-6.

7. Otsuji Y, Handschumacher MD, Schwammenthal E, Jiang L, Song JK, Guerrero JL, et al. Insights from three-dimensional echocardiography into the mechanism of functional mitral regurgitation. Circulation. 1997;96:1999-2008.

8. Popovic ZB, Martin M, Fukamachi K, Inoue M, Kwan J, Doi K, et al. Mitral annulus size links ventricular dilatation to functional mitral regurgitation. $J \mathrm{Am}$ Soc Echocardiogr. 2005;18:959-63.
9. Jorapur V, Voudouris A, Lucariello RJ. Quantification of annular dilatation and papillary muscle separation in functional mitral regurgitation: role of anterior mitral leaflet length as reference. Echocardiography. 2005;22:465-72.

10. Matsui Y, Suto Y, Shimura S, Fukada Y, Naito Y, Yasuda K, et al. Impact of papillary muscle approximation on the adequacy of mitral coaptation in functional mitral regurgitation due to dilated cardiomyopathy. Ann Thorac Cardiovasc Surg. 2005; 11:164-71.

11. Maisano F, Torracca L, Oppizzi M, Stefano PL, D'Addario G, La Canna G, et al. The edge-to-edge technique: a simplified method to correct mitral insufficiency. Eur J Cardiothorac Surg. 1998;13:240-5.

12. Palacios IF. Percutanous valve repair and replacement: fiction or reality? J Am Coll Cardiol. 2005;44:1662-3.

13. Kervancioglu M, Ozbag D, Kervancioglu P, Hatipoglu ES, Kilinc M, Yilmaz F, et al. Echocardiographic and morphologic examination of left ventricular false tendons in human and animal heart. Clin Anat. 2003;16:389-95.

14. Abdulla AK, Frustaci A, Martinez JE, Florio RA, Somerville J, Olsen EG. Echocardiographic and pathology of left ventricular "false tendons." Chest. 1990;98: 129-33.

15. Tamborini G, Pepi M, Celeste F, Muratori M, Susini F, Maltagliati A, et al. Incidence and characteristics of left ventricular false tendons and trabeculations in the normal and pathologic heart by second harmonic echocardiography. J Am Soc Echocardiogr. 2004; 17:367-74.

16. Deniz M, Kilinc M, Hatipoglu ES. Morphologic study of left ventricular bands. Surg Radiol Anat. 2004;26:230-4.

17. Suwa M, Hirota Y, Kaku K, Yoneda Y, Nakayama A, Kawamura K, et al. Prevalence of the coexistence of left ventricular false tendons and premature ventricular complexed in apparently healthy subjects: a prospective study in the general population. J Am Coll Cardiol. 1988;12:910-4.

18. Suwa M, Yoneda Y, Nagao H, Sakai Y, Nakayama Y, Hirota Y, et al. Surgical correction of idiopathic paroxysmal ventricular tachycardia possibly related to left ventricular false tendon. Am J Cardiol. 1989;64:1217-20.

19. Bhatt MR, Gardner B, Chiravuri R, Ferreira AC, de Marchena E. Effects of false tendons on mitral regurgitation in patients with severe left ventricular dysfunction [abstract]. J Am Coll Cardiol. 2006;47(suppl):40A.

20. McGinley JC, Berretta RM, Bratinov GD, Dhar S, Gaughan JP, Margulies KB. Subvalvular alterations promote increased mitral valve regurgitation in progressive dilated cardiomyopathy. J Card Fail. 2005;11:343-50.

21. Mihalatos DG, Mathew ST, Gopal AS, Joseph S, Grimson R, Reichek N. Relationship of mitral annular remodeling to severity of chronic mitral regurgitation. J Am Soc Echocardiogr. 2006;19:76-82.

22. Karagiannis SE, Karatasakis GT, Koutsogiannis N, Athanasopoulos GD, Cokkinos DV. Increased distance between mitral valve coaptation point and mitral annular plan: significance and correlations in patients with heart failure. Heart. 2003;89:1174-8.

23. Kongsaerepong V, Shiota M, Gillinov AM, Song JM, Fukuda S, McCarthy PM, et al. Echocardiographic predictors of successful versus unsuccessful mitral valve repair in ischemic mitral regurgitation. Am J Cardiol. 2006;98:504-8.

24. Calafiore AM, Gallina S, Di Mauro M, Gaeta F, Iaco AL, D'Alessandro S, et al. Mitral valve procedure in dilated cardiomyopathy: repair of replacement? Ann Thorac Surg. 2001;71:1146-53

25. Vinereanu D, Turner MS, Bleasdale RA, Mumford CE, Cinteza M, Frenneaux MP, et al. Mechanisms of reduction of mitral regurgitation by cardiac resynchronization therapy. J Am Soc Echocardiogr. 2007;20:54-62.

26. Bleeker GB, Schalij MJ, Molhoek SG, Verwey HF, Holman ER, Boersma E, et al. Relationship between QRS duration and left ventricular dyssynchrony in patients with end-stage heart failure. J Cardiovasc Electrophysiol. 2004;15: 544-9.

27. Young JB, Abraham WT, Smith AL, Leon AR, Lieberman R, Wilkoff B, et al. Combined cardiac resynchronization and implantable cardioversion defibrillation in advanced chronic heart failure: the MIRACLE ICD Trial. JAMA. 2003;289: 2685-94.

28. Inoue M, McCarthy PM, Popovic ZB, Doi K, Schenk S, Nemeh H, et al. The Coapsys device to treat functional mitral regurgitation: in vivo long-term canine study. J Thorac Cardiovasc Surg. 2004;127:1068-76.

29. Mishra YK, Mittal S, Jaguri P, Trehan N. Coapsys mitral annuloplasty for chronic functional ischemic mitral regurgitation: 1-year results. Ann Thorac Surg. 2006;81:42-6.

30. Fukamachi K, Inoue M, Popovic Z, Ootaki Y, Kopcak MW Jr, Dessoffy R, et al. Optimal mitral annular and subvalvular shape change created by the Coapsys device to treat functional mitral regurgitation. ASAIO J. 2005;51:17-21. 